\section{CONSERVATIVE MANAGEMENT OF METATARSAL FRACTURE IN A TIGER (PANTHERA TIGRIS)}

\author{
I. Nath ${ }^{1}$, V.S.C. Bose ${ }^{1}$, S.K. Panda ${ }^{1}$, R.K. Samantray ${ }^{2}$, \\ B. Mishra ${ }^{2}$ and P.K. Roy ${ }^{2}$
}

1 Orissa Veterinary College, Bhubaneshwar, Orissa, India

${ }^{2}$ Nandankanan Zoo, Orissa, India

A white Tiger "Rakesh" aged 13 years and weighing approximately $150 \mathrm{~kg}$ at Nandankanan Zoo developed lameness in its right hind limb. Oral analgesic (Tramadol hydrochloride $500 \mathrm{mg}$ ) and antibiotic (Ampoxin 500mg) in beef was administered for five days with no improvement. It was decided to examine the limb physically and radiologically.

A mixture of $0.65 \mathrm{mg}$ atropine sulphate, $150 \mathrm{mg}$ xylazine hydrochloride and $500 \mathrm{mg}$ ketamine hydrochloride was darted to the tiger using a pressure gun. After 10 minutes the animal was lifted on a tarpaulin strap to a transportation crate and shifted to the zoo hospital. Both the hind limbs were examined thoroughly for presence of wounds. Radiograph of both the limbs in lateral and dorsal-plantar views were taken starting from tarsal joints to digits. Radiographs revealed a simple incomplete fracture of right third metatarsal bone at its proximal third region.

Ringers' Lactate $500 \mathrm{ml}$ and DNS 5\% 500ml was administered intravenously. The heart rate, respiration rate and temperature varied within normal range during anaesthetic period. Antagozil $1.5 \mathrm{ml}(15 \mathrm{mg})$ was injected $\mathrm{i} / \mathrm{v}$ to revive the tiger from anaesthesia after shifting it in a squeeze cage. Cephotaxime $2 \mathrm{~g}$, Neurobion $2 \mathrm{ml}$, and Tramadol $2 \mathrm{ml}(200 \mathrm{mg})$ were injected intramuscularly for seven days. The tiger was kept in squeeze cage with limited movement for one month. Five powdered oral calcium tablets (shellcal-50) in beef was given during the period. The tiger recovered from lameness completely and was released to its enclosure.

In the present case since the fracture was incomplete and had no external wound, conservative management was thought to be proper. Dingwell (1974) suggested close reduction, if one or two metatarsal bones are fractured in dogs, with remaining bones acting as support. He further suggested coaptation splint or plaster cast for additional support. As external splints are rarely kept intact by wild animals, confinement of tiger inside a squeeze cage restricted its movement which helped in healing of the incomplete fracture.

\section{REFERENCE}

Dingwell, J.S. (1974). Fractures. In: J. Archibald (Editor). Canine Surgery $2^{\text {nd }}$ edition. American Veterinary Publication, Inc., 1015pp.

\section{ACKNOWLEDGeMent}

Authors are thankful to the Director, Nandankanan Zoo for according permission to do the work.

Manuscript 1111; Received 7 November 2003; Finally accepted 20 July 2004; @ Zoo Outreach Organisation; www.zoosprint.org 1670

\section{AMPUTATION OF WING IN A ROSY PELICAN (PELICANUS ONOCROTALUS)}

\author{
I. Nath ${ }^{1}$, V.S.C. Bose ${ }^{1}$, S.K. Panda ${ }^{1}$, R.K. Samantray ${ }^{2}$, \\ P.K. Roy ${ }^{2}$ and B. Mishra ${ }^{2}$ \\ 1 Orissa Veterinary College, Bhubaneshwar, Orissa, India \\ ${ }^{2}$ Nandankanan Zoo, Orissa, India
}

A Rosy Pelican aged about 21 years weighing $4.5 \mathrm{~kg}$ developed compound fracture of its right wing at the level of distal third radius and ulna. It was immobilised with wire suturing and bandaged after cleaning the site with povidone-iodine lotion (Betadine). Post operative topical and systemic antibiotic (Ampicillin+cloxacillin 125mg) with daily dressing was continued for 10 days. The wound developed sepsis and non-union with complete separation of distal part of the wing. It was decided to amputate the wing at a higher level. The pelican was anaesthetized with 50mg of ketamine hydrochloride injected intramuscularly. The bird was restrained in sitting posture. The site was prepared for aseptic surgery by plucking the feathers and washing the area with luke warm water and painting oxytetracycline (terramycin) liquid. The beak of the pelican was kept open to facilitate respiration. Throughout the operation $100 \mathrm{ml}$ of DNS $5 \%$ was infused intravenously into the wing vein. Amputation of the wing was carried out by raising the muscle flaps from a healthy area at about midshaft radius and ulna and cutting the bone with a wire saw. After pouring oxytetracycline (terramycin) liquid, the bone stump was covered with muscle flap on both sides and sutured using 4-0 chromic catgut with a swaged needle. The skin was stitched with fine nylon suture dipped in DMSO in mattress fashion. Then the stump was bandaged and retained in flexed condition by securing it to humerus. Cefotaxime $125 \mathrm{mg}$ b.i.d. intramuscularly was continued for five days based on the sensitivity test of the infected area. The stump was dressed daily with oxytetracycline and retained in flexed condition. After 15 days the skin stiches were removed. The pelican had an uneventful recovery.

In the present case, non-union of the compound fracture of radius and ulna might be due to inadequate rigid fixation and sepsis because of self-mutilation as observed by Bush (1986). As the pelican was an exhibit specimen in the zoo, amputation of the wing was thought to be the best solution to save its life. Nylon suture dipped in DMSO reduced irritation due to its antiinflammatory and antiseptic action in the healing process thereby preventing self-mutilation by the pelican. The pelican recovered completely with slight imbalance due to uneven wing span while walking.

\section{REFERENCE}

Bush, M. (1986). Laparoscopy and surgery. In: Zoo and Wild Animal medicine. $2^{\text {nd }}$ Edition, W.B. Saunders Company, Philadelphia, pp.254-255.

\section{ACKNOWLEDGEMENT}

Authors are thankful to the Director, Nandankanan Zoo for according permission to do the work.

Manuscript 1110; Received 7 November 2003; Finally accepted 20 July 2004; @ Zoo Outreach Organisation; www.zoosprint.org 